\title{
VERMAAK BIJ DE KERSENBLOESEMS
}

Er is een klein aantal voorwerpen in de Verenigingscollectie dat het depot niet kan verlaten, omdat de toestand ervan te slecht is. Een voorbeeld daarvan is het kamerscherm op afbeelding I (voorzijde) en 2 (achterzijde), een achtdelig scherm met vertier onder de kersenbloesems, hier afgebeeld in de oude toestand. Het is te zien dat het oppervlak vuil was en dat het oppervlak van zowel voor- als achterzijde op verschillende plaatsen was beschadigd. Bovendien waren de papieren scharnieren losgeraakt, waardoor het scherm niet meer kon staan. Het was dan ook fijn dat er in het museum middelen konden worden aangeboord die een volledige restauratie mogelijk maakten en eind 2016 kon begonnen worden met een complete hermontering van het scherm.

\section{Een kamerscherm van acht delen}

Dit is een bijzonder scherm omdat beide zijden van het scherm beschilderd zijn. Hoewel het twee jaargetijden zijn, lente en herfst, is het duidelijk zichtbaar dat de schilderingen niet direct met elkaar te maken hebben. De voorzijde met de hoofdvoorstelling van verschillende soorten vermaak bij de kersenbloesems is van een heel andere aard dan de voorstelling aan de achterzijde (afb. 2). De detaillering van de voorzijde is beduidend sterker, eleganter en verfijnder dan de wat slordige en losse penseelstreek van de achterzijde. De voorstelling op de achterzijde bestaat uit een ruim en schetsmatig opgezet landschap met als titel: Xiling akikururu ('Late herfst in Xiling'). In deze najaarsscène kleuren de heuvels rood van de esdoorns waar de Chinese streek Xiling bekend om staat. Ook de signatuur van de schilder is terug te vinden: Itabashi Takao hitsu ('geschilderd door Itabashi Takao'). Deze schilder kon tot op heden niet getraceerd worden. Ook is niet bekend wat de voor- en achterzijde met elkaar te maken hebben en of ze uit dezelfde tijd stammen.

\section{Voorstelling}

De schilderstijl van de scene op de voorzijde vertoont overeenkomsten met die van de school van Hishikawa Moronobu (I6I8-I694), een kunstenaar die veel genrevoorstellingen op zijn naam heeft staan. De stijl van ons kamerscherm kan wellicht rond I70o gedateerd worden. Links wordt gedanst onder de bloesems. Aan het wapen op de omheining te zien is dit een uitstapje van het bordeel Myōga-ya uit de Yoshiwara-wijk van Edo. Rechts wordt een toneelvoorstelling opgevoerd. De afscheidingen hier dragen een wapen van drie vlinders. 
Het scherm is in I93I door de VVAK verworven van de bekende kunsthandelaar Felix Tikotin (I893-I986).' Op een etiket op de achterzijde van het scherm staat verder: stamt [sic] von Fursten von Nagoya ('afkomstig van de vorst van Nagoya'). Een herkomst uit het bezit van de daimyo van Nagoya is intrigerend, maar kan nog niet geverifieerd worden. Dit etiket zou van de Japanse handelaar kunnen zijn, wellicht gemaakt ten behoeve van Tikotin die het scherm in Japan verworven kan hebben op een van zijn inkoopreizen. ${ }^{2}$

\section{Onderzoek}

Voor de restauratie moest er voorbereidend onderzoek gedaan worden, onder andere om een stappenplan op te stellen voor dit specifieke scherm. Daarnaast dient dit onderzoek als een pilotproject voor vier andere schermen van de VVAK die in te slechte conditie zijn om opgesteld te worden en die op de planning staan om gerestaureerd te worden. Voor dit onderzoek wordt het scherm bekeken met verschillende onderzoeksapparaten: Infrarood fotografie (IRR) en Ultra Violet fotografie (UV) voor het zichtbaar maken van overschilderingen en eerdere restauraties; Hirox digitale microscopie, Licht Microscopie (LM), Raman spectroscopie en XRF Röntgen fluorescentie (voor het pigmentonderzoek). Er worden uitsluitend monsters genomen in het geval dat de andere technieken geen uitsluitsel kunnen geven over de aard van de pigmenten en andere materialen. Eén monster werd onderzocht met Ultra High-Performance Liquid Chromatography (UHPLC) en één monster met Scanning Electron Microscopie (SEM). Het verslag hieronder geeft een overzicht van de eerste resultaten van dit onderzoek, dat op het moment van verschijnen van dit nummer nog in gang is, parallel lopend aan de restauratie.

\section{Het materiaal}

Een aantal aspecten van techniek en materiaalbehandeling van de voorzijde en de achterzijde verschillen duidelijk van elkaar. Het papier is anders, zo heeft de voorzijde een papiermaat van 27,5 bij 52 centimeter en bestaat uit vier vellen per paneel. Het is duidelijk dat de voorzijde passend is voor dit scherm. De achterzijde heeft een papiermaat van ongeveer 40 bij 52 centimeter en bestaat uit drie vellen per paneel en een extra onderrand die niet beschilderd is. Deze andere maatvoering van de papiervellen zou kunnen betekenen dat de achterzijde een latere toevoeging is die passend is gemaakt, maar dat is op dit moment nog niet te zeggen.

De kleuren die aan beide zijden gebruikt zijn, zien er op het eerste gezicht uit als traditionele Japanse pigmenten en kleurstoffen. De pigmenten en kleurstoffen werden met verschillende technieken onderzocht om duidelijkheid te krijgen over hun aard. Zoals te verwachten viel, zien we malachiet, vermiljoen, zwarte inkt, schelpenwit, zilver en goud. Deze minerale pigmenten zijn met verschillende methoden aangetoond. ${ }^{3}$ [LM, XRF en Hirox] Er is ook een aantal organische kleurstoffen gebruikt aan beide zijden van het scherm. Een van deze organische kleurstoffen is het roze van een kimono dat met UHPLC is onderzocht. ${ }^{4}$ Hetois karmijnlak gemaakt duit ${ }_{02}$ 12:35:53PM 

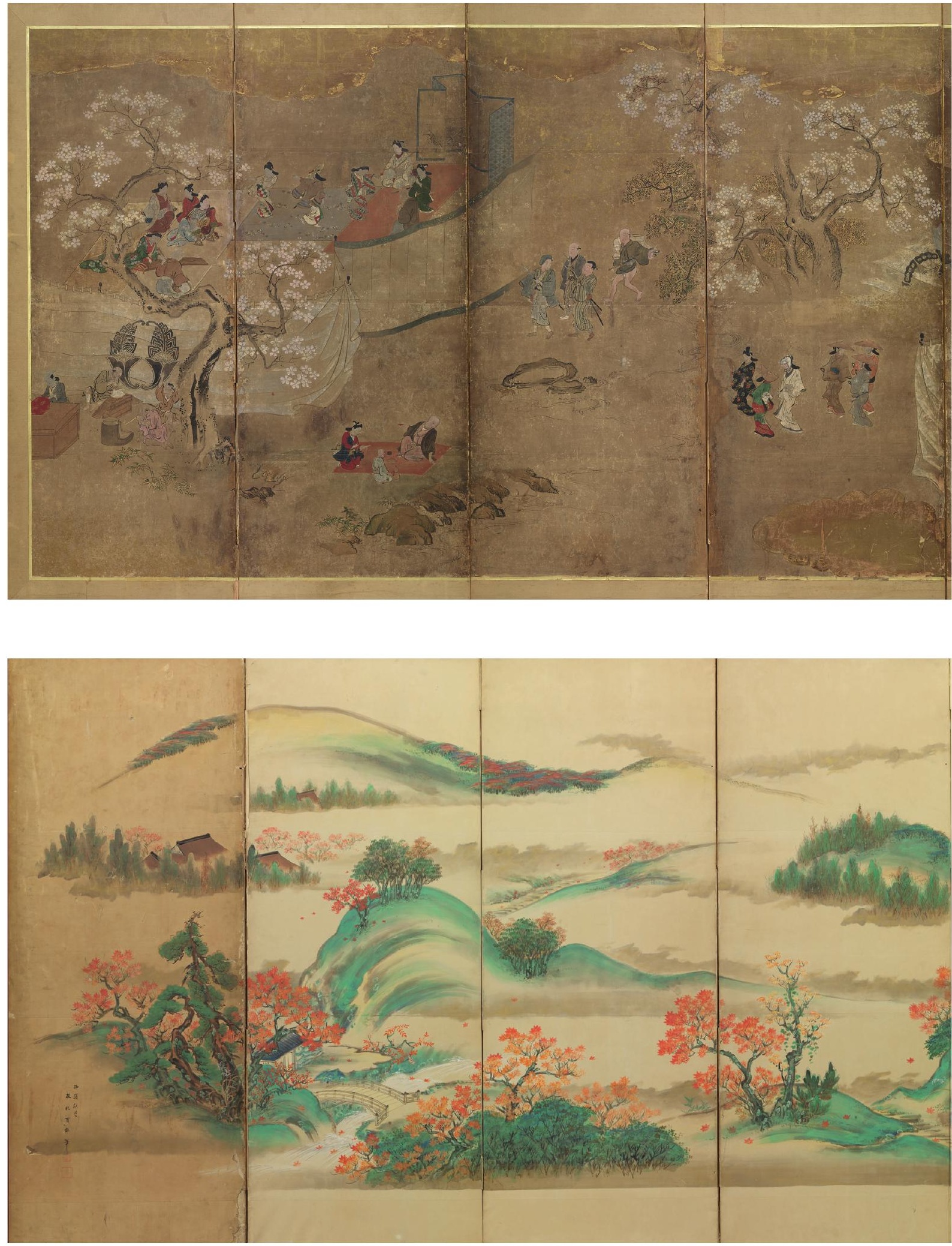

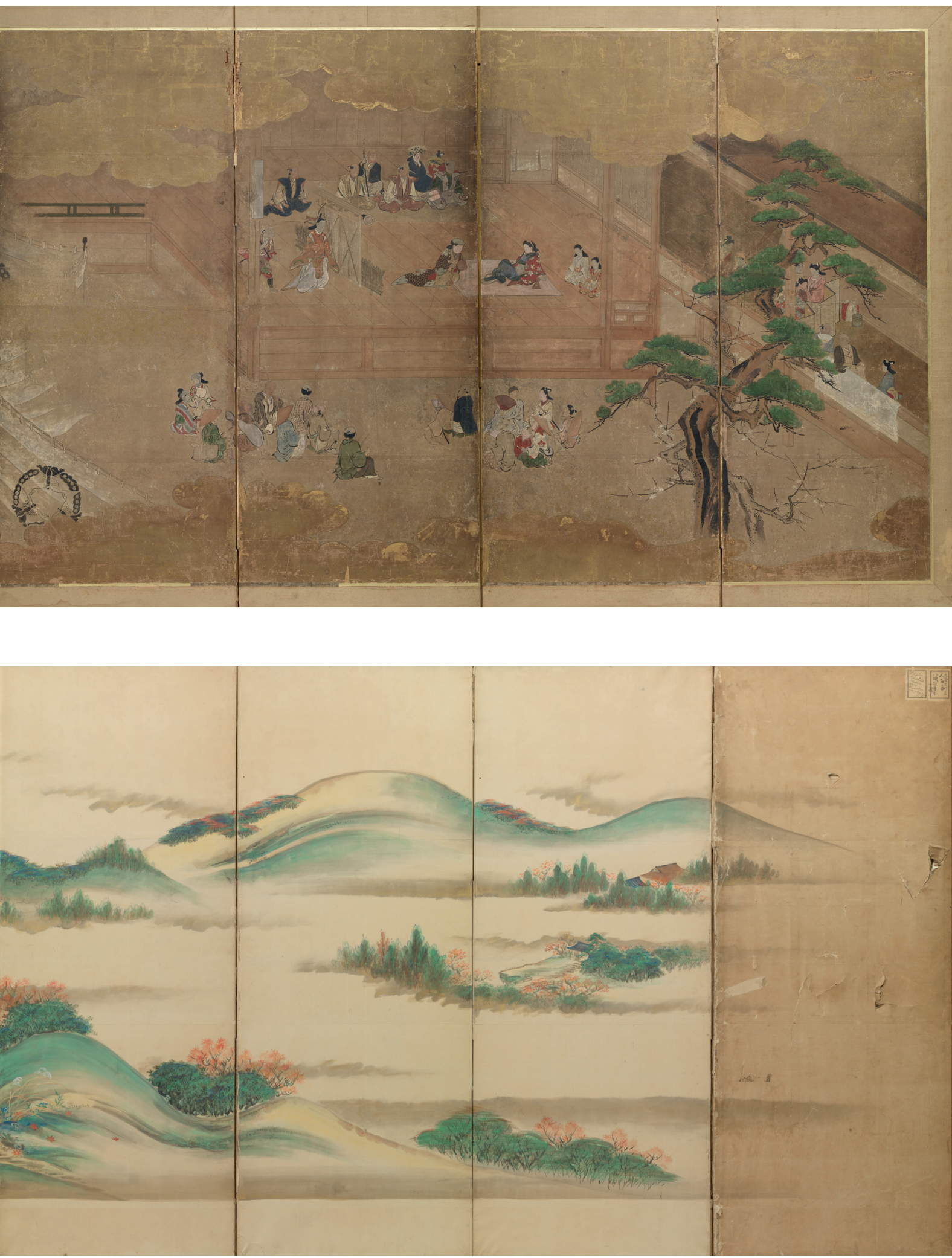


« Afb. 1
Vermaak bij de
kersenbloesems,
kamerscherm, inkt en
kleur op papier, 137
X $430 \mathrm{~cm}$, Japan, ca.
1700, Rijksmuseum
Amsterdam, inv.
nr. AK-MAK-171.
Bruikleen Vereniging
van Vrienden der
Aziatische Kunst
<< Afb. 2
Schildering aan de
achterzijde van het
scherm

cochenilleluizen waarbij tevens ook sporen van indigotine zijn gevonden in dit monster. Dat wijst op het gebruik van indigo in de omgeving van het roze.

De gezichten van de figuren hebben niet allemaal dezelfde kleur. Er zijn roze, bruine en grijze gezichten en dat roept vragen op over het materiaal. Grijskleurige gezichten zijn vaak het gevolg van veroudering en verkleuring van het gebruikte materiaal loodwit. Slechts op enkele plaatsen op het scherm, vooral in de kraag van een van de figuren (zie afb. 3) is loodwit gebruikt. Deze kraag is juist niet verkleurd, terwijl het gezicht van deze figuur wel een egaal grijze kleur heeft. Een verklaring hiervoor is nog niet gevonden. In een tabel met de verschillende perioden waarin pigmenten voorkomen in Japanse schilderingen en prenten, ${ }^{5}$ kunnen we terugvinden dat schelpenwit of oesterwit (gofun) het meest voorkomende wit was van de $16^{\mathrm{e}}$ tot midden $\mathrm{I}^{\mathrm{e}}$ eeuw. Loodwit werd vanaf de late $\mathrm{I} 8^{\mathrm{e}}$ eeuw meer gebruikt. ${ }^{6}$

Een mooi voorbeeld van het schelpenwit zien wij in de centrale groep bloemen van de landschapsschildering. Wuivende, witte pluimen afstekend tegen het malachiet op de heuvel en het goudpoeder van de gele kleur. Azuriet en vermiljoen komen voor in de bloemen, meer malachiet zien we in de struiken. De zwarte lijnen bestaan hoofdzakelijk uit inkt, wat wordt bevestigd door de aanwezigheid van carbon en ijzer. Zowel de grijsbruine vegen als de helder gele partijen in deze landschapsschildering bestaan uit goudpoeder, dat met lijm vermengd is, gebruikt als verf. Na de restauratie zal dit hopelijk weer nog duidelijker zichtbaar zijn.

Naast goudpoeder is ook zilver als verf gebruikt. Op de voorzijde staat een figuur met een rijkgedecoreerde, blauwe kimono (afb. 4). Tijdens het onderzoek bleek het blauw uit zilver te bestaan. Onder de microscoop zagen we dat het zilver in dit geval niet uit folie bestaat, maar uit losse, in lijm gevatte, deeltjes. Daarnaast is met de SEM zilver en zwavel gemeten. ${ }^{7}$ Normaal gesproken duidt dit op zilversulfide, maar dat is zwart. Het kwam niet overeen met de blauwe kleur die we hier zagen. Na enig zoeken bleek dat er in Japan een vorm van zilververf genaamd kungindei werd gebruikt. Dit bestaat uit zilverfolie dat eerst met een chemische reactie op zwavel is verkleurd tot blauw, rood of zwart. ${ }^{8}$ Daarna wordt het met dierlijke lijm of met een stijfselsiroop (imo'ame) fijngewreven tot kleine deeltjes. Vervolgens wordt het gezuiverd. De zo verkregen dei wordt gedroogd en door verhitting nog glanzender gemaakt (yakisuke). ${ }^{9}$

\section{Restauratie}

Het scherm wordt gerestaureerd door Andrew Thompson en Sydney Thomson van Restorient in Leiden, een werkplaats die gespecialiseerd is in de monteringstechnieken van Japanse schilderingen. Na de eerste visuele inspectie werd besloten om de acht panelen los van elkaar te halen. Bij restauratie is het loshalen (toch al) een standaardmethode omdat de papieren scharnieren in elk geval vervangen zullen worden. Dit vergemakkelijkte het onderzoek aanzienlijk, want een achtdelig scherm is niet eenvoudig onder de onderzoeksapparatuur te leggen.

Eenmaal uit elkaar gehaald konden de schilderingen van het frame worden genomen en kon het papier van de verschillende tussenlagen worden losgemaakt. Een Japans kamerscherm bestaat uit vierschillende be $_{23}$ 12:35:53PM 
Afb. 3

Witte kraag (loodwit) en grijs gezicht, detail afbeelding 1
Afb. 4

Blauwe versiering van zilverpigment op de kimono, detail afbeelding 1
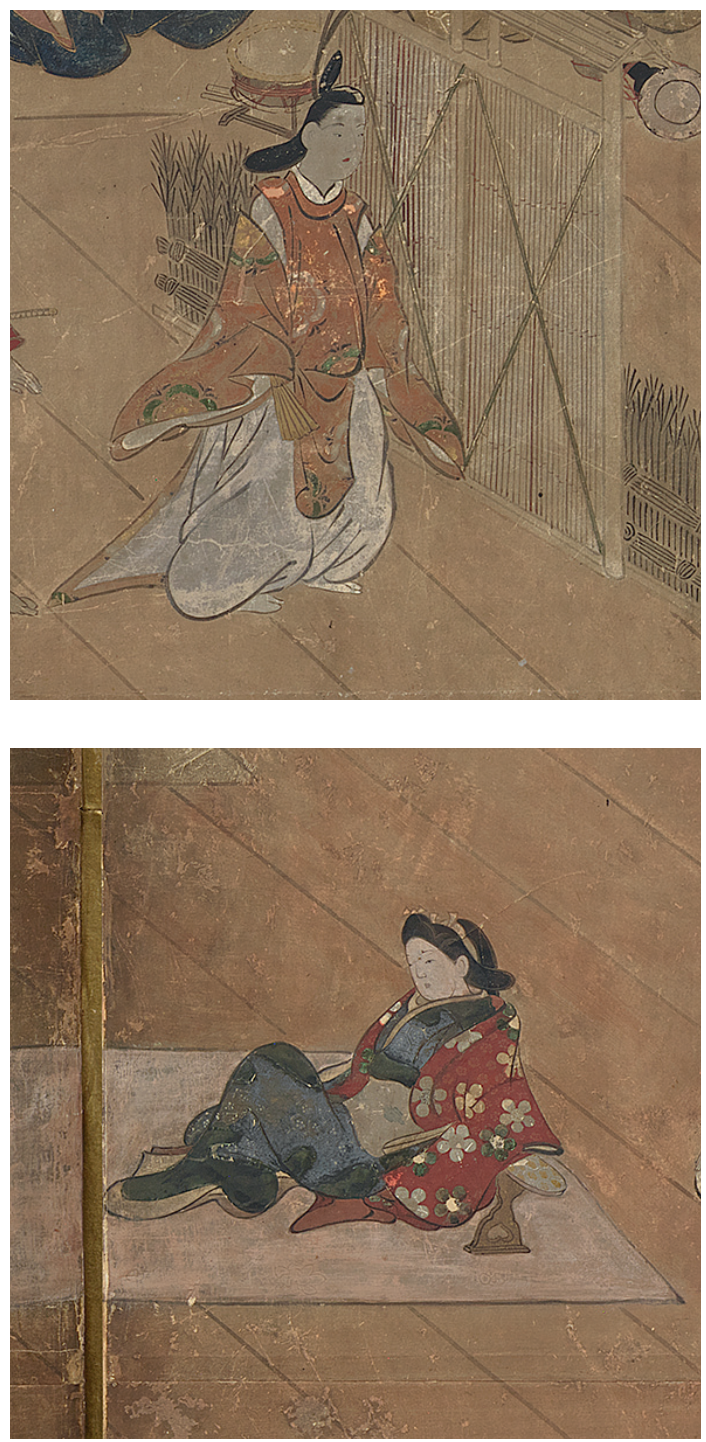

lagen papier op een houten frame. De papierlagen zijn op verschillende manieren opgespannen, zodat er een flexibele laag ontstaat die als buffer fungeert voor de bovenliggende schildering bij veranderingen in temperatuur of luchtvochtigheid. Het losgemaakte papier bleek van uitstekende kwaliteit te zijn. Op minstens een van de tussenlagen is kalligrafie te zien. Het is niet ongewoon om gebruikt papier te vinden, dat mooi zacht is. Het kan soms een indicatie geven van de locatie of tijdperiode van de laatste keer dat het scherm opnieuw opgespannen is. Op het frame bleek een bijzondere constructie te zijn gebruikt bij het aanbrengen van de lakrand (fuchi) (afb. 5). Tevens bleek er een extra versterkingsbord aangebracht te zijn aan de onderzijde van het inwendige frame. Gezien de staat van het frame werd besloten om een nieuw frame aan te brengen. Dit inwendige frame (kumiko) wordt gemaakt van speciaal Japans cederhout, een soort dat weinig harsen bevat en daardoor uiterst stabiel is en niet vervormt. 


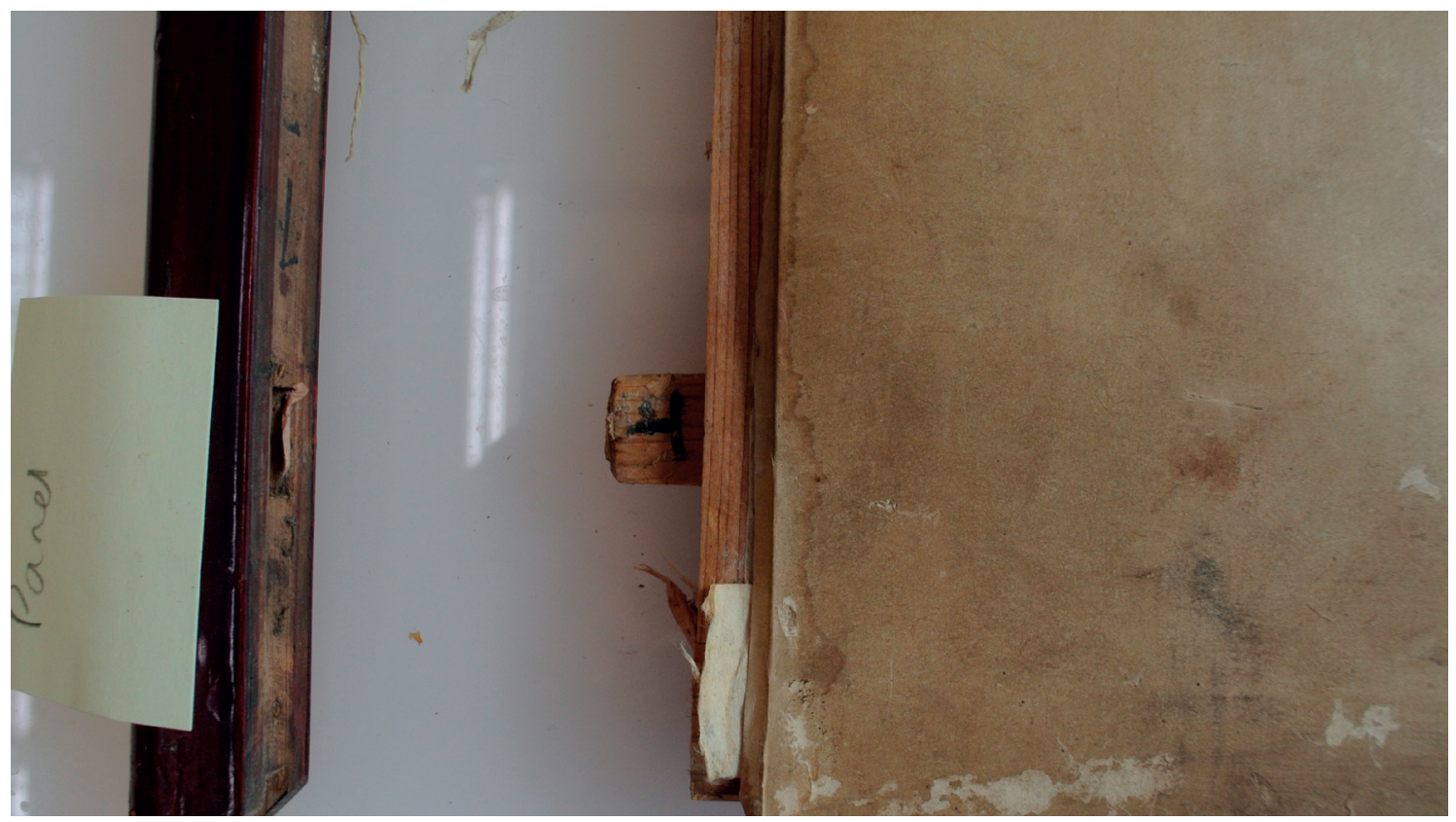

Afb. 5

De ongebruikelijke houtverbinding van het frame en de lakrand (fuchi)
Beide schilderingen waren behoorlijk vuil en op veel plaatsen is de verflaag fragiel. Pigmentverlies was dan ook een probleem dat behandeling vereiste. Verder bestond de schade uit zilvervisvraat, krassen en overschilderingen die vermoedelijk bij eerdere restauraties waren aangebracht. De partijen waar goud oorspronkelijk als bladgoud werd aangebracht, waren dof en vuil geworden, maar de sporen van de vierkante originele blaadjes bladgoud zijn nog herkenbaar. We zien op veel plaatsen beschadigingen in het goud die in het verleden zijn overschilderd, en op die plaatsen bevat het goud veel meer koper dan de originele blaadjes goud.

Aan de voorzijde bestaat ieder paneel oorspronkelijk uit vier vellen papier (maniai-shi) en ieder paneel is op de traditionele manier met lijm en aluin vervaardigd. Bij de restauratie wordt allereerst het vuil verwijderd. Hiervoor wordt de schildering losgemaakt van de achterliggende papierlagen en met de schildering naar boven neergelegd en nat gemaakt. Het vuil wordt er met de grootst mogelijke voorzichtigheid uitgehaald door absorberend papier eronder te leggen dat het vuil opzuigt. Vervolgens wordt de verflaag geconsolideerd om verder pigmentverlies tegen te gaan. Dit consolideren is een omzichtig proces dat op de pigmenten wordt toegepast en soms op de, ook aanwezige, organische kleurstoffen. Op deze kleurstoffen is het minder eenvoudig omdat sommige in water oplosbaar zijn. De plaatsen met loszittende verfdeeltjes worden een voor een behandeld met een hertenlijm oplossing (nikawa, I\% - 3\%). Vooral de ervaring van de restaurator komt hierbij om de hoek kijken. 
Binnenkort kunt u lezen welke resultaten er tijdens het onderzoek en de restauratie nog meer naar boven zijn gekomen. De restauratie van het scherm zal volgens planning in het voorjaar van 2017 voltooid worden, zodat het voorwerp na de wissel op I9 april 2017 voor het eerst in decennia weer in volle glorie in de opstelling te zien zal zijn.

- Lucien van Valen is sinoloog en schilder. Zij heeft zich gespecialiseerd in het onderzoek van techniek en materiaal van Aziatische kunst.

- Menno Fitski is conservator Oost-Aziatische Kunst. Naast de zorg voor de opstelling in het Aziatisch Paviljoen van het Rijksmuseum doet hij onderzoek naar Japans lakwerk en Kakiemon porselein.

\section{LITERATUUR}

Jaron Borensztajn, Ghosts and Spirits from the Tikotin Museum of Japanese Art: Felix Tikotin a Life Devoted to Japanese art, Leiden University Press, Leiden, 2012.

Sandra Grantham, 'Some Painting Techniques and Materials used in Japan and the Far East', The Paper Conservator 30/I, 2006, pp. II-24.

Sandra Grantham, 'Japanese Painted Paper Screens: Manufacturing Materials and Painting Techniques', Studies in Conservation 47/3, 2002, pp. 83-87.

Ikuo Hirayama et al., An Illustrated Dictionary of Japanese-style Painting Terminology, Tokyo Bijutsu, Tokyo, 2010.

Ikuo Hirayama et al., Restoration of Japanese Art in European and American Collections, Chuokoronsha, Tokyo, 1995.

Rokuru Ueyemura, 'Studies on Ancient Pigments in Japan', Eastern Art, 193I, pp. $47-60$.

Elisabeth West FitzHugh, John Winter and Marco Leona, 'Studies Using Scientific Methods: Pigments in Later Japanese Paintings', Freer Gallery of Art Occasional Papers, new series, vol. I, 2003.

Kazuo Yamasaki and Yoshimichi Emoto, 'Pigments used on Japanese Painting from the Protohistoric Period through the I7th Century', Ars Orientalis II, I979, pp. I-I4.

\section{NOTEN}

I Notulen bestuursvergadering I7 oktober I93I, archief VVAK I.

2 Voor Tikotin, zie Borensztajn 20I2. Het handschrift op het etiket lijkt niet van Tikotin te zijn.

3 XRF en LM, Arie Wallert.

4 UHPLC-rapport, Art Proaño Gaibor, 20-04-2016.

5 Fitzhugh 2003: 2.

6 Fitzhugh 2003: 2.

7 SEM uitgevoerd door Ineke Joosten, oI-09-20I6, RCE [Rijksdienst voor het Cultureel Erfgoed].

8 Hirayama 20I0: 63.

9 Hirayame 20I0: 73. 